\section{Survey on broiler pre-slaughter mortality in a commercial abattoir of central Italy}

\author{
Claudia Grilli, ${ }^{1}$ Roberta Stocchi, ${ }^{2}$ \\ Anna Rita Loschi, ${ }^{2}$ Fabrizio conti, ${ }^{3}$ \\ Stefano Rea $^{2}$ \\ ${ }^{1}$ Regional Health Authority, Marche \\ Region, Area Vasta 2, Ancona; ${ }^{2}$ School \\ of Biosciences and Veterinary Medicine, \\ University of Camerino, Matelica; \\ ${ }^{3}$ Regional Health Authority, Marche \\ Region, Area Vasta 2, Jesi, Italy
}

\begin{abstract}
The pre-slaughter mortality was investigated on broilers, in the Mediterranean climate condition, considering the most significant risk factors as the journey length, waiting time, season and the space allowance in cages. At first, the pre-slaughter mortality was studied considering the totality of birds and then by examining in detail three broiler categories: large, medium and small size. The average dead on arrival (DOA) recorded on the totality of birds throughout the year was $0.38 \%$ and the values obtained in winter, spring, summer and autumn were $0.52,0.48$, 0.31 and $0.22 \%$, respectively. The mortality rate observed during the year was $0.52,0.47$ and $0.31 \%$ for large, medium and small broilers, respectively. In all three groups, the maximum values of mortality were obtained in winter, whereas the minimum ones were recorded in autumn, spring and summer for large, medium, and small size birds, respectively. The increase of journey length could cause a higher mortality rate whereas the increase of the waiting time in the facilities at controlled environmental conditions did not seem to be a risk factor, but rather a mean to reduce the number of dead animals (all $\mathrm{P}<0.05$ ). It is concluded that the resistance to the hostile weather conditions, long journeys and extended waiting times was strongly related with the body weight of broilers; therefore, the planning of the slaughtering activity should consider this aspect, in order to avoid animal suffering and the economic loss.
\end{abstract}

\section{Introduction}

In the last day of their life, broilers are caught manually or with mechanical systems, put into the cages, loaded into the trucks and transported to the slaughterhouse to be sacrificed. All these operations can compromise the welfare, the health and the survival of animals. Catching machines are advantageous with regard to the cost of labor and they may also reduce damages to poultry (Knierim and Gocke, 2003), but there are contradictory reports if the manual or mechanic method is to be preferred (Schwartzkopf-Genswein et al., 2012). Indeed, some authors (Chauvin et al., 2011; Kittelsen et al., 2017) identified mechanical catching as a possible risk factor for broiler mortality. The incorrect practices of handling and transport can increase the incidence of dead on arrival (DOA) or rather the number of animals died between the catching and the slaughtering. The DOA is not considered only an indicator of welfare during catching, loading, transport and unloading but it also represents an economic loss (Ritz et al., 2005). In this regard, surveys conducted on broilers in different parts of the world show average rates of DOA between 0.11 and $0.46 \%$ (Gregory and Austin, 1992; Alshawabkeh and Tabbaa, 1997; Nijdam et al., 2004; Vecerek et al., 2006; Jacobs et al., 2017).

The EC Regulation No 1/2005 provides the recommendations regarding the protection of animals during the transport and related operations. During the transport, birds are exposed to a variety of stressors such as microenvironmental conditions, accelerations, vibrations, impacts, noise, fasting and withdrawal from water (Mitchell and Kettlewell, 1998; Abeyesinghe et al., 2001; Schwartzkopf-Genswein et al., 2012; Jacobs et al., 2017). The consequences of these stressors depend upon the age and type of birds concerned (EFSA, 2011). The major threat to animal welfare during trasport is the thermal condition (Weeks and Nicol, 2000; Elrom, 2001; Nilipour, 2002; Chauvin et al., 2011; Vecerek et al., 2016; Caffrey et al., 2017). Hour and method of catching, hour and length of journey, lairage duration, stocking density, age and sex of birds are possible risk factors for poultry mortality suggested by different authors (Bayliss and Hinton, 1990; Chauvin et al., 2011; Caffrey et al., 2017). Sick animals are more susceptible to transport stress because they are not able to cope with the adverse conditions (Knowles, 1994; Jacobs et al., 2017). The inspection of birds before the loading is essential to ensure their fitness for transport (EC Regulation No 1/2005). In the broiler, according to Nilipour (2002), the pre-existing flock health status, the injuries from catching, loading and transport, and the heat or cold stress contribute for 25, 35 and $40 \%$ to pre-slaughter mortality, respectively.

Stocking density is another crucial factor
Correspondence: Stefano Rea, Scuola di Bioscienze e Medicina Veterinaria, University of Camerino, Via Circonvallazione 93/95, 62024 Matelica (MC), Italy.

Tel.: +39.0737.403443 - Fax: +39.0737.403402

E-mail: stefano.rea@unicam.it

Key words: Food Inspection, Broiler, Mortality, Transport time, Waiting time, Season

Contributions: the authors contributed equally.

Conflict of interest: the authors declare no potential conflict of interests.

Funding: none

Received for publication: 21 May 2018

Revision received: 9 October 2018.

Accepted for publication: 12 October 2018

This work is licensed under a Creative Commons Attribution-NonCommercial 4.0 International License (CC BY-NC 4.0).

CCopyright C. Grilli et al., 2018

Licensee PAGEPress, Italy

Italian Journal of Food Safety 2018; 7:5878

doi:10.4081/ijfs.2018.5878

for bird welfare in the pre-slaughter phases whose increase can lead the relative humidity $(\mathrm{RH})$ due to water evaporation from the respiratory tract, skin and excreta to raise (Nijdam et al., 2004). This causes a more difficult heat loss and facilitates the hyperthermia during the hot season (Dawson and Whittow, 2000). According to the EC Regulation No 1/2005 (Annex I, chapter VII, point $\mathrm{E}$ ) the required surface for each $\mathrm{kg}$ of live weight in cage should be related also to the physical condition of birds, the weather and the likely journey time. This consideration is consistent with the EFSA opinion (2011) according to which the number of broilers in crates should be limited when external temperature is higher than $22^{\circ} \mathrm{C}$. On the other hand, in the colder seasons a high stocking density during the journey may have a beneficial effect: in this condition some metabolic heat would be produced warming the air and reducing the risk of death from hypothermia (Strawford et al., 2011; Caffrey et al., 2017).

After the transport, cages should be placed for a suitable lairage time in the holding area with environmental monitoring systems, in order to allow fresh air to circulate through the crates (Quinn et al., 1998). Nijdam et al. (2004) and Caffrey et al. (2017) proved that the risk of death raises as the lairage time increases. However, different authors (Petracci et al., 2006; Vieira et al., 2011; Grilli et al., 2015) found that the 
waiting time does not affect the mortality rate if the environmental conditions are controlled in the holding area.

The season significantly influences mortality, with the highest incidence in summer (Petracci et al., 2006; Vecerek et al., 2006) and in winter (Vecerek et al., 2006; Verecek et al., 2016). Heat stress as well as cold stress could be exacerbated by a long journey and inappropriate stocking density (EFSA, 2011; Caffrey et al., 2017; Jacobs et al., 2017). The genetic selection in broiler chickens has resulted in major improvements in growth rates and production efficiency but it was also associated with a reduced resistance to thermal stress (Broom, 2005; Sandercock et al., 2006; Mitchell and Kettlewell, 2009) and more in general to a worsening of their welfare status (Meluzzi and Sirri, 2009). Warriss et al. (1992) found that the broiler mortality was 0.156 and $0.283 \%$ for journey lasting less than 4 and more than $9 \mathrm{~h}$, respectively. These results are in accordance with the findings of Bianchi et al. (2005) according to which the poultry mortality for journey duration lower than 3.5 $\mathrm{h}$, between 3.5 and $5 \mathrm{~h}$ and longer than $5 \mathrm{~h}$ was $0.24,0.41$ and $0.45 \%$, respectively. In a similar study, Vecerek et al. (2006) found DOA rates of 0.146 and $0.862 \%$ for journey distances shorter than 50 and longer than 300 $\mathrm{km}$, respectively. According to Nielsen et al. (2011) the time spent on the vehicle seems to affect broiler mortality more than the distance driven. Finally, Nijdam et al. (2004) observed a higher rate of mortality for large broilers respect to small ones.

Since few scientific researches regarding the pre-slaughter mortality in different broilers types were conducted in the Mediterranean climatic conditions, further investigations could be useful. For this reason, the present survey was focused on the values of DOA recorded in three different size categories of broilers (small, medium and large) slaughtered throughout a whole solar year in a processing plant of Central Italy. Particular attention was paid to the effects of the weather conditions, the journey length and the waiting time in the abattoir, on the pre-slaughter mortality for different broiler sizes.

\section{Materials and Methods}

The evaluation of the main risk factors associated to broiler pre-slaughter mortality was carried out analysing the documentation of 2012 slaughter activity, held by the Official Veterinary Authority. No direct experiments were realized to animals.

\section{Broilers}

The survey covered all the batches of Ross broilers conferred between 2 January and 31 December 2012 to an industrial poultry abattoir, placed in the Marche Region with a slaughter capacity of about 80,000 heads per day. A total of 22,315,729 broilers (2,266 batches) were examined, of which 5,670,360 males at $53 \mathrm{~d}(632$ batches), 2,353,621 males and females at 46 d (346 batches) and 14,291,748 females at $35 \mathrm{~d}$ (1,288 batches), with an average live weight of about $3.50 \mathrm{~kg}$ (large size), $2.70 \mathrm{~kg}$ (medium size) and $1.67 \mathrm{~kg}$ (small size), respectively. Table 1 shows the seasonal distribution of broilers and batches conferred to the abattoir for each live weight category.

\section{Origin of broilers, loading and transport system}

The animals came from farms located mainly in regions of the central Italy (Marche, Umbria, Lazio and Abruzzo), all equipped with mechanical caging systems in modular crates $(1.20 \mathrm{~m} \times 1.40 \mathrm{~m} \times 0.30 \mathrm{~m})$ of plastic material with perforated walls and floor for ventilation (4 S-5 S, Stork, Germany).

The transport was performed by trucks with passive ventilation at different times of the day with the exception of large size broilers which were transported mostly at night.

\section{Waiting Time}

After the unloading, the cages were transferred by forklift truck in the waiting shed, consisting in an area delimited by three roofed walls. This area was equipped with a cooling system consisting in panels through which a flow of cold water was automatically activated when the internal temperature of the holding area exceeded $20^{\circ} \mathrm{C}$ and in 19 fans with an air flow of $30,000 \mathrm{~m}^{3} / \mathrm{h}$ each (Gigola and Riccardi Spa, Italy). The broilers were uncaged and slaughtered within $12 \mathrm{~h}$ of arrival.

\section{Data processing and statistical analyses}

For each batch the following data were recorded and stored in a database: date of slaughtering, place of departure, time of loading, time of arrival, number of animals for batch, average body weight, journey time, waiting time, number of animals found dead at the time of uncaging, and the space at floor on cages for each broiler. Data were obtained from the transport documents and from the electronic slaughter register, filled out daily by the Official Veterinarians.

In order to find the impact of the weather conditions on poultry pre-slaughter mortality, the DOA rates referred to the totality of broilers and to the three different size categories were calculated in winter, spring, summer and autumn.

Moreover, the study was completed by grouping the data referred to the journey length in 4 categories $(<2,2-4,4-6$ and 6-12 $\mathrm{h})$, and those referred to the waiting time in 5 clusters $(<2,2-4,4-6,6-8$ and $8-12$ h) to investigate the effects of these two risk factors on mortality percentage. As for journey length, the time spent on the vehicle was chosen as a measure instead of the distance driven because the former seems to affect broiler mortality at a higher extent (Nielsen et al., 2011). Finally, the space allowance in cages was calculated and compared to values established by the EC Regulation No $1 / 2005$. The values of live weight $(\mathrm{kg})$ were obtained by multiplying the average body weight of broilers for the average number of animals in one cage. The available space for each $\mathrm{kg}$ of live weight was found by dividing the value of the crate surface to the previously calculated value.

The descriptive statistical analysis was performed using the Microsoft Office Excel software (Microsoft Co., Redmond, WA, USA). The minimum, weighted average, maximum values and standard deviations of the journey length, waiting time and mortality were calculated for the totality of birds and for each broiler category. Moreover, for each value of DOA referred to the totality of broilers from different batches subjected to the same journey length and lairage time, the mean value and standard deviation were calculated in order to study their effects on the mortality rate during the

Table 1. Seasonal distribution of broilers and batches conferred to the abattoir for each size category.

\begin{tabular}{lccccc}
\multirow{2}{*}{ Large } & & Winter & Spring & Summer & Autumn \\
& n. broilers & $1,429,616$ & $1,449,508$ & $1,363,270$ & $1,427,966$ \\
\multirow{2}{*}{ Medium } & n. batches & 151 & 164 & 160 & 157 \\
& n. broilers & 632,623 & 599,840 & 610,436 & 510,722 \\
& n. batches & 79 & 90 & 98 & 79 \\
\hline \multirow{2}{*}{ Small } & n. broilers & $3,225,428$ & $3,616,848$ & $3,438,903$ & $4,010,569$ \\
& n. batches & 301 & 334 & 338 & 315 \\
\hline
\end{tabular}


different seasons. This consideration was carried out for the three broiler categories, examined in the study. It must be pointed out that the standard deviation was not calculated when the totality of broilers belonged to a single batch only. The statistical significance of the research was also determined by the calculation of the $\mathrm{P}$ value, considering the seasonal mortality percentage as the reference parameter.

\section{Results}

\section{Dead on arrival}

The mean incidence of DOA found throughout the year was $0.38 \%$, with minimum and maximum values of 0 and $11.70 \%$, respectively. Specifically, the average values of DOA observed in winter, spring, summer and autumn were $0.52,0.48$, 0.31 and $0.22 \%$, respectively. Moreover, a mortality rate of $0.52,0.47$ and $0.31 \%$ was recorded in large, medium and small broilers, respectively. The percentage of mortality, for each broiler size category, during different seasons is presented in the Figure 1. Table 2 summarises the minimum, mean, maximum values and standard deviation of the journey length, waiting time and mortality for the totality of broilers and for the three weight categories.

\section{Journey length and waiting time}

Results show that the transport and lairage length lasted overall $7.12 \mathrm{~h}$ on average. Further analyses of results indicate that the transport and lairage duration were less than 6 , from 6 to 8 , from 8 to 12 and over than $12 \mathrm{~h}$ for the $36.7,28.6,28.2$ and $6.5 \%$ of broilers, respectively. The percentages of broilers, which travelled for less than 2, between 2 and 4, 4 and 6, 6 and $12 \mathrm{~h}$ were $48.7,37.3,9.8$ and $4.2 \%$, respectively. Therefore, the journey duration

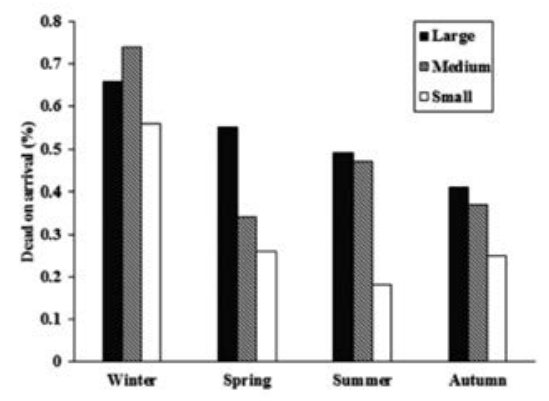

Figure 1. Seasonal average mortality rate of large, medium and small broilers conferred to the abattoir. was less than $4 \mathrm{~h}$ for the $86 \%$ of animals. The $19,31.4,26.2,16.6$ and $6.8 \%$ of birds were subjected to a waiting time of less than 2 , from 2 to 4,4 to 6,6 to 8 and 8 to $12 \mathrm{~h}$, respectively.

Data on the influence of the journey length and the lairage time on DOA of the three broiler sizes, during the different seasons, are reported in Tables 3-5. In these Tables the $\mathrm{P}$ value (lower than 0.01 or 0.05 ) was specified for each mortality rate. It must be pointed out that all reported values were highly significant $(\mathrm{P}<0.01)$ with the exception of the average mortality percentage observed in medium broilers transported for $6-12 \mathrm{~h}$ after a waiting time less than $2 \mathrm{~h}$, during summer (Table 4).

\section{Space allowance in cages and sea- sonal average temperature}

The space allowance in cages for each

Table 2. Journey length, waiting time and mortality values for the totality of broilers and for each size category.

\begin{tabular}{llcccc}
\multirow{2}{*}{ Total } & Minimum & $\begin{array}{c}\text { Mean } \\
\text { Value* }\end{array}$ & $\begin{array}{c}\text { Maximum } \\
\text { value }\end{array}$ & $\begin{array}{c}\text { Standard } \\
\text { deviation }\end{array}$ \\
& Journey length (h) & $0.05^{* *}$ & 2.16 & 10.36 & 1.43 \\
& Waiting time (h) & $0^{* * *}$ & 4.56 & 12.00 & 2.24 \\
\multirow{2}{*}{ Large } & Mortality (\%) & 0 & 0.38 & 11.70 & 0.57 \\
& Journey length (h) & $0.06^{* *}$ & 2.08 & 10.15 & 1.31 \\
& Waiting time (h) & 1.00 & 5.58 & 12.00 & 2.11 \\
& Mortality (\%) & 0 & 0.52 & 11.70 & 0.64 \\
\hline \multirow{2}{*}{ Medium } & Journey length (h) & $0.06^{* *}$ & 2.21 & 6.20 & 1.41 \\
& Waiting time (h) & 1.00 & 6.00 & 12.00 & 3.01 \\
& Mortality (\%) & 0 & 0.47 & 5.30 & 0.60 \\
& Journey length (h) & $0.05^{* *}$ & 2.18 & 10.36 & 1.48 \\
& Waiting time (h) & $3^{* * *}$ & 4.22 & 12.00 & 2.22 \\
& Mortality (\%) & 0 & 0.31 & 7.18 & 0.50 \\
\hline
\end{tabular}

*Values referring to a weighted average based on the number of birds which compose the batch. **Values concerning broiler flocks coming from farms next to the abattoir. ${ }^{* * *}$ Data referring to poultry batches slaughtered immediately after their arrival.

Table 3. Average mortality percentages with standard deviation of large broilers, subjected to different journey lengths and waiting times in the four seasons.

\begin{tabular}{|c|c|c|c|c|c|}
\hline Journey & & & g time & & \\
\hline$<2 h$ & $0.69 \pm 0.94^{\mathrm{a}}$ & $0.29 \pm 0.11^{\mathrm{a}}$ & $0.74 \pm 0.69^{\mathrm{a}}$ & $0.51 \pm 0.37^{\mathrm{a}}$ & $0.60 \pm 0.50^{\mathrm{a}}$ \\
\hline $2-4 \mathrm{~h}$ & $0.91 \pm 0.5^{b}$ & $0.73 \pm 1.10^{\mathrm{a}}$ & $0.65 \pm 0.55^{\mathrm{a}}$ & $0.47 \pm 0.21^{\mathrm{a}}$ & $0.84 \pm 0.67^{\mathrm{a}}$ \\
\hline $4-6 \mathrm{~h}$ & $0.36^{*}$ & $0.33 *$ & $1.21 \pm 1.21^{\mathrm{a}}$ & $0.93 \pm 0.27^{\mathrm{a}}$ & $1.29 *$ \\
\hline $6-12 \mathrm{~h}$ & $1.93^{*}$ & I & $1.32 \pm 0.27^{\mathrm{a}}$ & $1.94 *$ & I \\
\hline & & Sp & & & \\
\hline$<2 h$ & $0.32 \pm 0.14^{\mathrm{a}}$ & $0.34 \pm 0.27^{\mathrm{a}}$ & $0.48 \pm 0.50^{\mathrm{a}}$ & $0.47 \pm 0.44^{\mathrm{a}}$ & $0.36 \pm 0.23^{\mathrm{a}}$ \\
\hline $2-4 \mathrm{~h}$ & $0.16 \pm 0.09^{a}$ & $0.40 \pm 0.40^{\mathrm{a}}$ & $0.41 \pm 0.24^{\mathrm{a}}$ & $0.57 \pm 0.40^{\mathrm{a}}$ & $0.69 \pm 0.84^{a}$ \\
\hline $4-6 \mathrm{~h}$ & $0.69 \pm 0.54^{\mathrm{a}}$ & $0.65 \pm 0.73^{\mathrm{a}}$ & $0.47 \pm 0.30^{\mathrm{a}}$ & $0.44 \pm 0.09^{a}$ & $0.55^{*}$ \\
\hline $6-12 \mathrm{~h}$ & $0.39 \pm 0.21^{\mathrm{a}}$ & $0.78 \pm 0.82^{\mathrm{a}}$ & $0.24 \pm 0.23^{\mathrm{a}}$ & I & I \\
\hline & & Sun & & & \\
\hline$<2 \mathrm{~h}$ & $0.34 \pm 0.06 \mathrm{a}$ & $0.29 \pm 0.19 a$ & $0.56 \pm 0.48 \mathrm{a}$ & $0.43 \pm 0.31 \mathrm{a}$ & $0.36 \pm 0.10 \mathrm{a}$ \\
\hline $2-4 \mathrm{~h}$ & $0.46 \pm 0.52^{\mathrm{a}}$ & $0.50 \pm 0.40^{\mathrm{a}}$ & $0.42 \pm 0.37^{\mathrm{a}}$ & $0.74 \pm 0.53^{\mathrm{a}}$ & $0.50 \pm 0.42^{\mathrm{a}}$ \\
\hline $4-6 \mathrm{~h}$ & $0.11 \pm 0.06^{\mathrm{a}}$ & $0.41 \pm 0.15^{\mathrm{a}}$ & $0.39 \pm 0.29^{a}$ & 1 & / \\
\hline $6-12 \mathrm{~h}$ & $0.21 \pm 0.05^{\mathrm{a}}$ & $0.36 \pm 0.01^{\mathrm{a}}$ & $0.22 \pm 0.12^{\mathrm{a}}$ & I & I \\
\hline & & Aut & & & \\
\hline$<2 \mathrm{~h}$ & $0.23 \pm 0.06^{\mathrm{a}}$ & $0.33 \pm 0.33^{\mathrm{a}}$ & $0.41 \pm 0.26^{\mathrm{a}}$ & $0.57 \pm 0.55^{\mathrm{a}}$ & $0.89 \pm 0.11^{\mathrm{a}}$ \\
\hline $2-4 \mathrm{~h}$ & $0.19 \pm 1.35^{\mathrm{a}}$ & $0.30 \pm 0.19^{a}$ & $0.41 \pm 0.25^{\mathrm{a}}$ & $0.39 \pm 0.13^{\mathrm{a}}$ & I \\
\hline $4-6 \mathrm{~h}$ & $0.44 \pm 0.09^{\mathrm{a}}$ & $0.91 \pm 0.98^{\mathrm{a}}$ & I & $0.38 *$ & I \\
\hline $6-12 \mathrm{~h}$ & I & I & I & I & I \\
\hline
\end{tabular}

Different letters within the same column showed statistically significant differences for $\mathrm{P}<0.01^{\mathrm{a}}$ or $\mathrm{P}<0.05^{\mathrm{b}}$. * Value referred to a single batch of broilers. 
$\mathrm{kg}$ of large, medium and small broilers and the values recommended by EC Regulation No $1 / 2005$ are indicated in Table 6. Finally, Table 7 shows the mean temperature recorded in 2012 in Marche Region and the average values registered in the same area in the period 1961-2000 in the different seasons (ASSAM, Centro Operativo Agrometeorologia, Regione Marche).

\section{Discussion}

\section{Dead on arrival}

The average DOA considering all the three broiler sizes was $0.38 \%$ and the lowest DOA values were observed in autumn. Similarly, Petracci et al. (2006) and Vieira et al. (2011) reported an average mortality rate of 0.35 and $0.33 \%$, respectively, and the lowest values in the same season. Similar mortality rates $(0.37$ and $0.39 \%$, respectively) were reported also by Vecerek et al. (2016) in Czeck Republic and by Caffrey et al. (2017) in Canada. However, in this research summer and winter exhibited, respectively, lower and higher mortality rates than the values reported in the studies of Petracci et al. (2006), who carried out the survey in Italy in the same climatic conditions as those reported here, and Vieira et al. (2011), who performed the research in Brasil, under different climate. The results of the present study agree with the outcomes of different authors (Tabbaa and Alshawabkeh, 2000; Vecerek et al., 2016), who noted the highest mortality of broilers in winter even in very different climatic conditions (in Czeck Republic and Jordan, respectively).

The highest number of DOA was observed during winter in all the three broiler groups but was variable in the other seasons as summarized in Figure 1. The mortality of small size broilers was minimum in summer, intermediate and similar in spring/autumn, and was constantly the lowest in all seasons among the three size categories. Medium size chickens showed the minimum DOA values in spring, higher in summer and intermediate in autumn, and the maximum values among the three groups in winter.

The mortality rate in the large size group showed a gradual reduction from winter to autumn and was the highest among the three groups in spring, summer and autumn.

\section{Large broilers}

For journey length lower than $4 \mathrm{~h}$, the mortality in summer was not affected by the waiting time. Large broilers could wait for long time before slaughtering without significant consequences. Otherwise, for
Table 4. Average mortality percentages with standard deviation of medium broilers, subjected to different journey lengths and waiting times in the four seasons.

\begin{tabular}{|c|c|c|c|c|c|}
\hline \multicolumn{3}{|c|}{ Journey length } & \multicolumn{3}{|c|}{$\begin{array}{l}\text { Waiting time } \\
\text { ter }\end{array}$} \\
\hline$<2 \mathrm{~h}$ & $0.23 \pm 0.07^{a}$ & $0.25 \pm 0.17^{\mathrm{a}}$ & $0.50 \pm 0.61^{\mathrm{a}}$ & $0.54 \pm 0.53^{\mathrm{a}}$ & $0.83 \pm 0.56^{\mathrm{a}}$ \\
\hline $2-4 h$ & $0.84 \pm 0.54^{\mathrm{a}}$ & $0.53 \pm 0.37^{\mathrm{a}}$ & $1.18 \pm 0.89^{a}$ & $0.73 \pm 0.63^{a}$ & $0.60 \pm 0.23^{a}$ \\
\hline $4-6 \mathrm{~h}$ & $0.32^{*}$ & $0.16^{*}$ & $1.57 \pm 0.20^{\mathrm{a}}$ & $0.13^{*}$ & $2.44 \pm 0.48^{a}$ \\
\hline $6-12 \mathrm{~h}$ & I & I & 1 & I & I \\
\hline \multicolumn{6}{|c|}{ Spring } \\
\hline$<2 \mathrm{~h}$ & $0.09 \pm 0.06^{\mathrm{a}}$ & $0.32 \pm 0.30^{\mathrm{a}}$ & $0.29 \pm 0.28^{\mathrm{a}}$ & $0.37 \pm 0.31^{\mathrm{a}}$ & $0.39 \pm 0.19^{a}$ \\
\hline $2-4 \mathrm{~h}$ & $0.26 \pm 0.28^{a}$ & $0.36 \pm 0.37^{a}$ & $0.46 \pm 0.43^{\mathrm{a}}$ & $0.51 \pm 0.56^{\mathrm{a}}$ & $0.65 \pm 0.67^{a}$ \\
\hline $4-6 h$ & $0.32 \pm 0.17^{\mathrm{a}}$ & $0.35 \pm 0.33^{\mathrm{a}}$ & $0.41 \pm 0.33^{\mathrm{a}}$ & $0.92 \pm 0.38^{\mathrm{a}}$ & $0.82 \pm 0.72^{\mathrm{a}}$ \\
\hline $6-12 \mathrm{~h}$ & l & $0.31 \pm 0.29^{a}$ & $0.24 \pm 0.14^{\mathrm{a}}$ & $0.23 \pm 0.24^{\mathrm{a}}$ & $0.42 \pm 0.37^{a}$ \\
\hline \multicolumn{6}{|c|}{ Summer } \\
\hline$<2 h$ & $0.04 \pm 0.03 \mathrm{a}$ & $0.32 \pm 0.24^{a}$ & $0.32 \pm 0.22^{\mathrm{a}}$ & $0.69 \pm 0.72^{\mathrm{a}}$ & $0.62 \pm 0.48^{a}$ \\
\hline $2-4 \mathrm{~h}$ & $0.35 \pm 0.28^{a}$ & $0.42 \pm 0.44^{\mathrm{a}}$ & $0.39 \pm 0.39^{a}$ & $0.64 \pm 0.74^{\mathrm{a}}$ & $0.75 \pm 0.53^{\mathrm{a}}$ \\
\hline $4-6 \mathrm{~h}$ & $0.28 \pm 0.14^{a}$ & $0.12^{*}$ & $0.25 \pm 0.15$ & I & $0.57 \pm 0.43^{\mathrm{a}}$ \\
\hline $6-12 \mathrm{~h}$ & $5.30^{*}$ & $0.23^{*}$ & 1 & I & l \\
\hline \multicolumn{6}{|c|}{ Autumn } \\
\hline$<2 h$ & $0.16^{*}$ & $0.13 \pm 0.01^{\mathrm{a}}$ & $0.60 \pm 0.55^{\mathrm{a}}$ & $0.33 \pm 0^{\mathrm{a}}$ & $0.37 \pm 0^{\mathrm{a}}$ \\
\hline $2-4 \mathrm{~h}$ & $0.54^{*}$ & $0.37 \pm 0.31^{\mathrm{a}}$ & $0.49 \pm 0.25^{\mathrm{a}}$ & $0.41^{*}$ & $0.35 \pm 0.08^{a}$ \\
\hline $4-6 \mathrm{~h}$ & $0.30 \pm 021^{\mathrm{a}}$ & $0.65 \pm 0.35^{\mathrm{a}}$ & $0.66 \pm 0.43^{\mathrm{a}}$ & $0.92 \pm 0.38^{\mathrm{a}}$ & / \\
\hline $6-12 \mathrm{~h}$ & I & $0.55 \pm 0.36$ & I & I & I \\
\hline
\end{tabular}

Different letters within the same column showed statistically significant differences for $\mathrm{P}<0.01^{\mathrm{a}}$ or $\mathrm{P}<0.05^{\mathrm{b}}$. * Value referred to a single batch of broilers

Table 5. Average mortality percentages with standard deviation of small broilers, subjected to different journey lengths and waiting times in the four seasons.

\begin{tabular}{|c|c|c|c|c|c|}
\hline \multicolumn{2}{|c|}{ Journey length } & \multicolumn{3}{|c|}{$\begin{array}{l}\text { Waiting time } \\
\text { Winter }\end{array}$} & \multirow[b]{2}{*}{$0.28 \pm 0.24^{a}$} \\
\hline$<2 \mathrm{~h}$ & $0.23 \pm 0.21^{\mathrm{a}}$ & $0.27 \pm 0.24^{\mathrm{a}}$ & $0.23 \pm 0.16^{\mathrm{a}}$ & $0.31 \pm 0.33^{\mathrm{a}}$ & \\
\hline $2-4 \mathrm{~h}$ & $0.52 \pm 1.37^{b}$ & $0.55 \pm 0.57^{\mathrm{a}}$ & $0.43 \pm 0.34^{\mathrm{a}}$ & $1.06 \pm 1.38^{\mathrm{a}}$ & $0.68 \pm 0.71^{\mathrm{a}}$ \\
\hline $4-6 \mathrm{~h}$ & $1.14 \pm 1.03^{\mathrm{a}}$ & $1.18 \pm 1.02^{\mathrm{a}}$ & $2.10 \pm 1.80^{a}$ & $0.88 \pm 0.70^{a}$ & $1.18 \pm 0.35^{\mathrm{a}}$ \\
\hline $6-12 \mathrm{~h}$ & $2.46 \pm 3.09^{a}$ & $0.49 \pm 0.50^{\mathrm{a}}$ & $0.36 \pm 0.26^{\mathrm{a}}$ & $1.75 \pm 1.84^{\mathrm{a}}$ & $1.41 \pm 1.65^{\mathrm{a}}$ \\
\hline \multicolumn{6}{|c|}{ Spring } \\
\hline$<2 \mathrm{~h}$ & $0.24 \pm 0.23^{\mathrm{a}}$ & $0.24 \pm 0.18^{\mathrm{a}}$ & $0.32 \pm 0.29^{\mathrm{a}}$ & $0.23 \pm 0.21^{\mathrm{a}}$ & $0.09 \pm 0.08^{a}$ \\
\hline $2-4 \mathrm{~h}$ & $0.31 \pm 0.35^{\mathrm{a}}$ & $0.23 \pm 0.15^{\mathrm{a}}$ & $0.24 \pm 0.23^{\mathrm{a}}$ & $0.15 \pm 0.14^{\mathrm{a}}$ & $0.20 \pm 0.13^{\mathrm{a}}$ \\
\hline $4-6 \mathrm{~h}$ & $0.22 \pm 0.16^{\mathrm{a}}$ & $0.53 \pm 0.67^{\mathrm{a}}$ & $0.35 \pm 0.40^{\mathrm{a}}$ & l & I \\
\hline $6-12 \mathrm{~h}$ & I & $0.51 \pm 0.38^{\mathrm{a}}$ & I & I & I \\
\hline \multicolumn{6}{|c|}{ Summer } \\
\hline$<2 h$ & $0.11 \pm 0.13 \mathrm{a}$ & $0.16 \pm 0.18^{a}$ & $0.12 \pm 0.08^{a}$ & $0.23 \pm 0.17^{\mathrm{a}}$ & $0.14 \pm 0.13^{\mathrm{a}}$ \\
\hline $2-4 \mathrm{~h}$ & $0.18 \pm 0.17^{\mathrm{a}}$ & $0.17 \pm 0.16^{\mathrm{a}}$ & $0.26 \pm 0.20^{\mathrm{a}}$ & $0.19 \pm 0.18^{\mathrm{a}}$ & $0.20 \pm 0.23^{\mathrm{a}}$ \\
\hline $4-6 \mathrm{~h}$ & $0.20 \pm 0.28^{a}$ & $0.14 \pm 0.10^{\mathrm{a}}$ & $0.24 \pm 0.29^{\mathrm{a}}$ & $0.20 \pm 0.20^{\mathrm{a}}$ & $0.21 \pm 0.15^{\mathrm{a}}$ \\
\hline 6-12 h & $0.29 \pm 0.22^{\mathrm{a}}$ & $0.20 \pm 0.22^{\mathrm{a}}$ & $0.12 \pm 0.06^{\mathrm{a}}$ & l & $0.21 \pm 0.019 a$ \\
\hline \multicolumn{6}{|c|}{ Autumn } \\
\hline$<2 \mathrm{~h}$ & $0.13 \pm 0.12^{\mathrm{a}}$ & $0.13 \pm 0.09^{a}$ & $0.11 \pm 0.11^{\mathrm{a}}$ & $0.12 \pm 0.13^{\mathrm{a}}$ & $0.12 \pm 0.10^{\mathrm{a}}$ \\
\hline $2-4 \mathrm{~h}$ & $0.23 \pm 0.21^{\mathrm{a}}$ & $0.18 \pm 0.13^{\mathrm{a}}$ & $0.18 \pm 0.13^{a}$ & l & $0.22 \pm 0.13^{\mathrm{a}}$ \\
\hline $4-6 \mathrm{~h}$ & $0.18 \pm 0.14^{a}$ & $0.53 \pm 0.84^{\mathrm{a}}$ & $0.10 \pm 0.02^{\mathrm{a}}$ & $0.11 \pm 0.01^{\mathrm{a}}$ & I \\
\hline $6-12 \mathrm{~h}$ & $0.56 \pm 0.79^{a}$ & l & I & l & l \\
\hline
\end{tabular}

Different letters within the same column showed statistically significant differences for $\mathrm{P}<0.01^{\mathrm{a}}$ or $\mathrm{P}<0.05^{\mathrm{b}}$. 
journey length over $4 \mathrm{~h}$, it is recommended to slaughter those animals within $2 \mathrm{~h}$ after their arrival into the plant. However, the waiting time before slaughtering had a reduced impact on the mortality rates in any case, probably thanks to the positive effects of the environmental control system in lairage facility. During winter, the DOA of large broilers was negatively influenced by long journeys. The transport longer than $6 \mathrm{~h}$ was always associated to the highest mortality rate within the same group. On the contrary, the lairage duration did not affect the DOA, which did not present significant increasing trends. During spring and autumn, the negative correlation between the waiting time and the mortality rate was evident only for batches transported for 2-4 $\mathrm{h}$ and less than $2 \mathrm{~h}$, respectively.

\section{Medium broilers}

In summer the mortality of medium broilers was not influenced by the transport length. The waiting time up to $6 \mathrm{~h}$ had not a negative impact on DOA, whereas longer intervals caused a relevant increase of mortality. Therefore, the benefits of the cooling system in the waiting shed were not evident in medium broilers subjected to a lairage longer than $6 \mathrm{~h}$. During winter, the lowest values of DOA were associated to travels shorter than $2 \mathrm{~h}$ and waiting times up to $4 \mathrm{~h}$. Journeys longer than $2 \mathrm{~h}$ caused a mortality rate regularly above the average value. The negative impact of waiting time on DOA was observed in spring and autumn for the journey lengths of 2-4 $\mathrm{h}$ and 4-6 $\mathrm{h}$, respectively, whereas the transport duration affected the mortality in the case of waiting times less than $2 \mathrm{~h}$ and of 6-8 h, respectively.

Table 6. Space allowance $\left(\mathrm{cm}^{2}\right)$ in cages for each $\mathrm{kg}$ of live weight recorded in the present study and values recommended by EC Regulation No 1/2005.

\begin{tabular}{lcc} 
Broiler size & Space allowance in cages recorded & Values recommended $^{2}$ \\
Large & 187.85 & 115 \\
Medium & 188.27 & 160 \\
\hline Small & 191.36 & 160
\end{tabular}

'The values of live weight $(\mathrm{kg})$ were obtained by multiplying the average body weight of broilers for the average number of animals in one cage. The available space for each $\mathrm{kg}$ of live weight was found by dividing the value of the crate surface to the previously calculated value. ${ }^{2}$ The EC Regulation No 1/2005 provides that the minimum floor areas for each kg of poultry are 160 and $115 \mathrm{~cm} 2$ for weight ranges 1.6-3 and 3-5 kg, respectively.

Table 7. Average values of external temperature in Marche Region: comparison between 2012 and the period 1961-2000.

\begin{tabular}{lcccc} 
& Winter & Spring & Summer & Autumn \\
$2012\left({ }^{\circ} \mathrm{C}\right)$ & 4.8 & 13.1 & 24.9 & 15.3 \\
$1961-2000\left({ }^{\circ} \mathrm{C}\right)$ & 5.3 & 11.9 & 21.5 & 14.2 \\
\hline
\end{tabular}

Data from ASSAM, Centro Operativo Agrometeorologia, Regione Marche. lairage facility is a practical approach to reduce the mortality because it allows the birds to return to thermal balance and therefore enhance the survival rate.

Data collection pointed out the greater resistance of small birds to long journeys and waiting times, indeed the mortality rate of this poultry group is generally lower than the two others. Contrary to the results reported by Prado-Rebolledo et al. (2012), journey length and lairage time could have a negative impact on broiler mortality. As reported by some authors (Elsayed, 2014; Caffrey et al., 2017), the outcomes demonstrated that the increase of transport duration could cause a higher mortality rate, whereas the extension of the lairage time under controlled conditions did not seem to be a risk factor. Although the summer temperature in 2012 was $3.4^{\circ} \mathrm{C}$ higher than the seasonal average value recorded in the previous four decades, the mortality rate was moderate, probably due to the efficiency of the environmental control system on lairage facilities. On the opposite side, the winter temperature was $0.5^{\circ} \mathrm{C}$ lower than the historical mean data, and the DOA was significantly above the values noted in the other seasons and in the study conducted by Petracci et al. (2006) in the same climatic conditions. During 2012, the mean temperature and DOA of spring were $2.2^{\circ} \mathrm{C}$ lower and $26 \%$ higher than the values observed in autumn, respectively.

In the present study journey length up to $2 \mathrm{~h}$ and lairage time up to $2 \mathrm{~h}$ showed constantly low mortality rates with the exception of large broilers, particularly in winter. Differently, some authors (Vecerek et al., 2016) observed that birds transported over short distances (up to $50 \mathrm{~km}$ ) showed a higher mortality than those transported over longer distances (from 51 to $100 \mathrm{~km}$ ). This observation can be explained assuming that during short transport broilers do not have sufficient time to recover partially from the stress of handling, loading and travelling (Vosmerova et al., 2010), and considering that it takes about one hour (Voslarova et al., 2011). Anyway, it must be pointed out that mortality rates after short journeys (less than $50 \mathrm{~km}$ ) can be strongly affected by transport carried out directly by farmers to whom EC Regulation No 1/2005 does not apply.

Although long journey is more likely to compromise animal welfare than short one (Nijdam et al., 2004; Vecerek et al., 2006; Voslarova et al., 2007; Vecerek et al., 2016), it is not the only factor involved as demonstrated by Nielsen et al. (2011). Chauvin et al. (2011) did not observe any effect of transport length on DOA, probably due to the short distances recorded in their study ( $75 \mathrm{~km}$ on average). Obviously, the pre-slaughter mortality is not only related to 
the environmental conditions, physiological characteristics of birds, design of transport means and processing plants but also to the competence and experience of all the personnel involved in animal handling and transport (Caffrey et al., 2017).

\section{Space allowance in cage}

The space allowance in crates for each $\mathrm{kg}$ of poultry observed in the present study was higher than the value established by EC Regulation No $1 / 2005$. It must be pointed out that the respect of this aspect is a crucial factor to safeguard animal welfare (Nielsen et al., 2011) and thus DOA percentage (Chauvin et al., 2011; Jacobs et al., 2017).

\section{Conclusions}

In conclusion, the observation of high DOA percentage is an important issue for poultry industry not only because of the relevant economic loss in itself, but also considering that a high DOA value is related with many factors that can raise and act at any step of poultry production chain, from the farm to the slaughterhouse. Indeed, a wide number of risk factors associated with DOA have been identified and some of them not directly related to the transportation process.

In case of adverse thermal conditions, it is recommended that small broilers are handled and transported instead of medium and large birds because the mortality rate of the first group is clearly lower for all seasons of the year, compared with the other two groups. Otherwise, extra measures should be taken for transport carried out under cold temperatures, as suggested by Vecerek et al. (2016).

The planning of the slaughtering activity should consider the relationship between the resistance to the hostile weather conditions, journey durations, waiting times and the body weight of broilers. Finally, the control of the environmental conditions on lairage facilities and the evaluation of the weather forecast, especially in the planning of long transports, can help to reduce the DOA due to thermal stress.

In order to help all operators (farmers, drivers, local veterinarians, abattoir staff, transport organizers, competent authorities and policy makers) to ensure sufficient protection for the animals being transported by providing practical tools to meet the requirements of the Regulation and to deliver practices which go beyond legislation, a guide for the transport of poultry, commissioned by DG SANTE, has been recently produced within the framework of the Animal Transport Guides
Project (Consortium of the Animal Transport Guides Project, 2017). Its main aim was to develop and disseminate good and better practices for transportation also to reduce pre-slaughter losses.

Finally, the considerable complexity of the topic makes many further studies necessary to investigate deeper and deeper all aspects involved in affecting preslaughter mortality in broilers in order to help farmers and operators to identify the most significant ones and to prevent them at all steps of production chain.

\section{References}

Abeyesinghe SM, Wathes CM, Nicol CJ, Randall JM, 2001. The aversion of broiler chickens to concurrent vibrational and thermal stressors. Anim Behav Sci 73:199-215.

Alshawabkeh K, Tabbaa MJ, 1997. Factors affecting mortality and losses during transportation of broiler chickens from farms to processing plants in Jordan. Diras Agric Sci 24:53-61.

Bayliss PA, Hinton MH, 1990. Transportation of broilers with special reference to mortality rates. Appl Anim Behav Sci 28:93-118.

Bianchi M, Petracci M, Cavani C, 2005. Effects of transport and lairage on mortality, liveweight loss and carcass quality in broiler chickens. Ital J Anim Sci 4(Suppl 2):516-8.

Broom MD, 2005. The effects of land transport on animal welfare. Scientific and Technical Review of the Office International des Epizooties (Paris), 24:683-91.

Caffrey NP, Dohoo IR, Cockram MS, 2017. Factors affecting mortality risk during transportation of broiler chickens for slaughter in Atlantic Canada. Prev Vet Med 147:199-208.

Chauvin C, Hillion S, Balaine L, Michel V, Peraste J, Petetin I, Lupo C, Le Bouquin S, 2011. Factors associated with mortality of broilers during transport to slaughterhouse. Animal 5(2):287-93.

Consortium of the Animal Transport Guides Project, 2017. Good practices for animal transport in the EU: poultry. SANCO/2015/G3/SI2.701422.

Dawson WR, Whittow GC, 2000. Regulation of body temperature. Sturkie's Avian Physiology, 343-90.

EC REGULATION No $1 / 2005$ OF 22 DICEMBER 2004 Council Regulation (EC) No $1 / 2005$ on the protection of animals during transport and related operations and amending Directives 64/432/EEC, 93/119/EC, and Regulation (EC) No 1255/97. Official Journal of the
European Union No L 3 of 5 January 2005.

Elsayed MA, 2014. Effects of length of shipping distance and season of the year temperature stress on death rates and physiological condition of broilers on arrival to slaughterhouse. J Nuc Tec Appl Sci 2:453-63.

EFSA AHAW Panel, 2011. Scientific opinion concerning the welfare of animals during transport. EFSA Journal 125(9):1966.

Elrom K, 2001. Handling and transportation of broiler welfare, stress, fear and meat quality. Isr J Vet Med 56(2):41-4.

Gregory NG, Austin SD, 1992. Causes of trauma in broilers arriving dead at poultry processing plants. Vet Rec 131:501-3.

Grilli C, Loschi AR, Rea S, Stocchi R, Leoni L, Conti F, 2015. Welfare indicators during broiler slaughtering. Br Poult Sci 56(1):1-5.

Jacobs L, Delezie E, Duchateau L, Goethals K, Tuyttens FAM, 2017. Broiler chickens dead on arrival: associated risk factors and welfare indicators. Poultry Sci 96:259-65.

Kittelsen KE, Moe RO, Hoel K, Kolbjørnsen Ø, Nafstad O, Granquist EG, 2017. Comparison of flock characteristics, journey duration and pathology between flocks with a normal and a high percentage of broilers "dead-on-arrival" at abattoirs. Animal 11(12):2301-8.

Knierim U, Gocke A, 2003. Effects of catching broilers by hand or machine on rates of injuries and dead on arrivals. Anim Welf 12:63-73.

Knowles TG, 1994. Handling and transport of spent hens. World's Poult Sci J 50:601.

Meluzzi A, Sirri F, 2009. Welfare of broiler chickens. Ital J Anim Sci 8(Suppl 1):161-73.

Mitchell MA, Kettlewell PJ, 1998. Physiological stress and welfare of broiler chickens in transit: solutions not problems! Poult Sci 77:1803-14.

Mitchell MA, Kettlewell PJ, 2009. Welfare of poultry during transport - a review. Proceedings of the Poultry Welfare Symposium, 2002 May 18-22, Cervia, Italy.

Nielsen BL, Dybkjaer L, Herskin S, 2011. Road transport of farm animals: effects of journey duration on animal welfare. Animal 5:415-27.

Nijdam E, Arens P, Lambooij E, Decupere E, 2004. Factors influencing bruises and mortality of broilers during catching, transport and lairage. Poult Sci 83:16105.

Nilipour AH, 2002. Poultry in transit are a 
cause for concern. World Poult 18(2):303.

Petracci M, Bianchi M, Cavani C, Gaspari P, Lavazza A, 2006. Preslaughter mortality in broiler chickens, turkeys and spent hens under commercial slaughtering. Poult Sci 85(9):1660-4.

Prado-Rebolledo O, Morales-Barrera E, Macedo-Barragan R, Contreras-Lara D, 2012. Effects of time of water and feed withdrawal, catching, transport and lairage on broiler mortality in the state of Mexico. J Anim Prod Adv 2:405-8.

Quinn AD, Kettlewell PJ, Mitchell MA, Knowles T, 1998. Air movement and the thermal microclimates observed in poultry lairages. Br Poult Sci 39:469-76.

Ritz CW, Webster AB, Czarick M, 2005. Evaluation of hot weather thermal environment and incidence of mortality associated with broiler live haul. J Appl Poult Res 14:594-602.

Sandercock DA, Hunter RR, Mitchell MA, Hocking PM, 2006. Thermoregulatory capacity and muscle membrane integrity are compromised in broilers compared with layers at the same age or body weight. Br Poult Sci 47(3):322-9.

Schwartzkopf-Genswein KS, Faucitano L, Dadgar S, Shand P, Gonzalez LA, Crowe
TG, 2012. Road transport of cattle, swine and poultry in North America and its impact on animal welfare, carcass and meat quality: a review. Meat Sci 92:22743.

Strawford ML, Watts JM, Crowe TG, Classen HL, Shand PJ, 2011. The effect of simulated cold weather transport on core body temperature and behaviour of broilers. Poult Sci 90(11):2415-24.

Tabbaa MJ, Alshawabkeh K, 2000. Some factors affecting preslaughtering mortality and damage to broilers and interaction during transportation to processing plants. Diras Agric Sci 27:375-84.

Vecerek V, Grbalova S, Voslarova E, Janackova B, Malena M, 2006. Effects of travel distance and the season of the year on death rates of broilers transported to poultry processing plants. Poult Sci 85:1881-4.

Vecerek VC, Voslarova E, Conte F, Vecerkova L, Bedanova I, 2016. Negative trends in transport-related mortality rates in broiler chickens. Asian-Australas J Anim Sci 29(12):1796-804.

Vieira FMC, Silva IJO, Barbosa Filho JAD, Vieira AMC, Broom DM, 2011.
Preslaughter mortality of broilers in relation to lairage and season in a subtropical climate. Poult Sci 90:212733.

Voslarova E, Chloupek P, Vosmerova P, Chloupek J, Bedanova I, Vecerek V, 2011. Time course changes in selected biochemical indices of broilers in response to pretransport handling. Poult Sci 90(10):2144-52.

Vosmerova P, Chloupek J, Bedanova I, Chloupek P, Kruzikova K, Blahova J, Vecerek V, 2010. Changes in selected biochemical indices related to transport of broilers to slaughterhouse under different ambient temperatures. Poult Sci 89(12):2719-25.

Warriss P, Bevis EA, Brown SN, Edwards JE, 1992. Longer journeys to processing plants are associated with higher mortality in broiler chickens. Br Poult Sci 33:201-6.

Weeks C, Nicol C, 2000. Poultry handling and transport. In: Grandin $\mathrm{T}$, ed. Livestock handling and transport. Second Edition. CAB International, Wallingford, UK, pp 363-84. 